\title{
Anesthetic implications in patients with myasthenia gravis undergoing spine surgery
}

\author{
Bhanupreet Kaur ${ }^{1}$, Gurpreet Singh ${ }^{2}$, Haramritpal Kaur ${ }^{3}$, Inderpreet Singh ${ }^{4}$ \\ From ${ }^{1}$ Senior Resident, Department of Anaesthesia, GGS Medical College and Hospital, ${ }^{2}$ Professor, ${ }^{3}$ Associate Professor, ${ }^{4}$ Junior Resident, Department \\ of Anaesthesia, Medical College and Hospital, Faridkot, Punjab, India
}

\begin{abstract}
Myasthenia gravis is a chronic autoimmune disorder affecting post-synaptic neuromuscular junction. It is characterized by skeletal muscle weakness and fatigability which improves with rest. The anesthesiologists may encounter these patients for thymectomy or sometimes for incidental surgeries. However, it is a real challenge for anesthesiologists because of the unpredictable response with muscle relaxants and analgesics and the possibility of ventilatory complications. In the present case report, we report the management of a 52-year-old female patient with myasthenia gravis who is posted for schwannoma surgery.
\end{abstract}

Key words: Anesthesia, Autoimmune, Myasthenia gravis, Neuromuscular junction, Schwannoma

$\mathrm{M}$ yasthenia gravis is a chronic autoimmune neurological disorder that affects post-synaptic neuromuscular junction [1]. Thymic abnormalities have been associated with the genesis of antibodies against motor endplate nicotinic receptors. These antibodies lead to activation of the complement system which destroys and decreases functional receptors at neuromuscular junction [2]. Myasthenia gravis affects females more than males and usually in their third decade of life [3]. Its incidence and prevalence are estimated to be $3-10$ and $0.25-2 \%$ per 100,000 population [4]. It is usually associated with other autoimmune disorders such as diabetes mellitus, rheumatoid arthritis, and hypothyroidism, systemic lupus erythematosus, and Sjogren syndrome [5]. The most common disorder that complicates the myasthenia gravis is hyperthyroidism [6]. The characteristic features of the disease are skeletal muscle weakness and fatigability which improves with rest [7]. Anesthesiologists may encounter these patients for thymectomy or sometimes for incidental surgeries. Myasthenia gravis poses a special challenge for anesthesiologists because of the unpredictable response associated with muscle relaxants and analgesics and the possibility of ventilatory complications [8].

In this case report, we hereby present the management of a female patient of myasthenia gravis posted for lumbar schwanoma surgery. Application of the anesthetic technique without muscle relaxants, in the prone position with about $4 \mathrm{~h}$ of surgery. This

\section{Access this article online}

Received - 04 February 2021

Initial Review - 24 February 2021

Accepted - 01 April 2021

DOI: 10.32677/IJCR.2021.v07.i04.001 technique prevented post-operative respiratory complications, as well as, there was no requirement for mechanical ventilation.

\section{CASE REPORT}

A 52-year-old female, weighing $100 \mathrm{~kg}$, height 5' 6" presented with a complaint of radiating pain in the left leg Since seven years for which magnetic resonance imaging was done and the patient was diagnosed having an intradural extramedullary lesion at L3 with a tentative diagnosis of schwannoma (Fig. 1). The patient was a known case of myasthenia gravis with acetylcholine receptor antibodies positive to a value of $42.8 \mathrm{nmol} / 1$ (considered positive if value $>0.50$ ). The patient was on tablet pyridostigmine

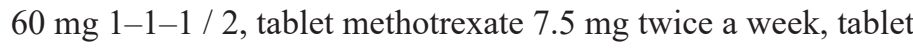
folic acid $5 \mathrm{mg}$ twice a week, and tablet aspirin $75 \mathrm{mg}$ once a day. The patient was having no respiratory symptoms at presentation or in past and the metabolic equivalent of task score at present was more than 4. On examining the patient, she had no pallor, icterus, clubbing, lymphadenopathy, or edema.

All the routine investigations along with pulmonary function tests were done. The patient was found to have subclinical hyperthyroidism. Free T3 (FT3) and free T4 (FT4) were within normal limits $(2.76 \mathrm{pg} / \mathrm{ml}$ and $1.22 \mathrm{ng} / \mathrm{dL}$, respectively), whereas, thyroid-stimulating hormone was $0.311 \mu \mathrm{IU} / \mathrm{ml}$ (normal 0.45-4.5).

Preoperatively, all the medications were continued. Written informed high-risk consent along with post-operative ventilatory and intensive care unit (ICU) stay consent was taken. Blood

Correspondence to: Bhanupreet Kaur, Department of Anaesthesia, GGS Medical College and Hospital, Faridkot, Punjab, India. E-mail: bhanupreet.768@gmail.com

(C) 2021 Creative Commons Attribution-NonCommercial 4.0 International License (CC BY-NC-ND 4.0). 


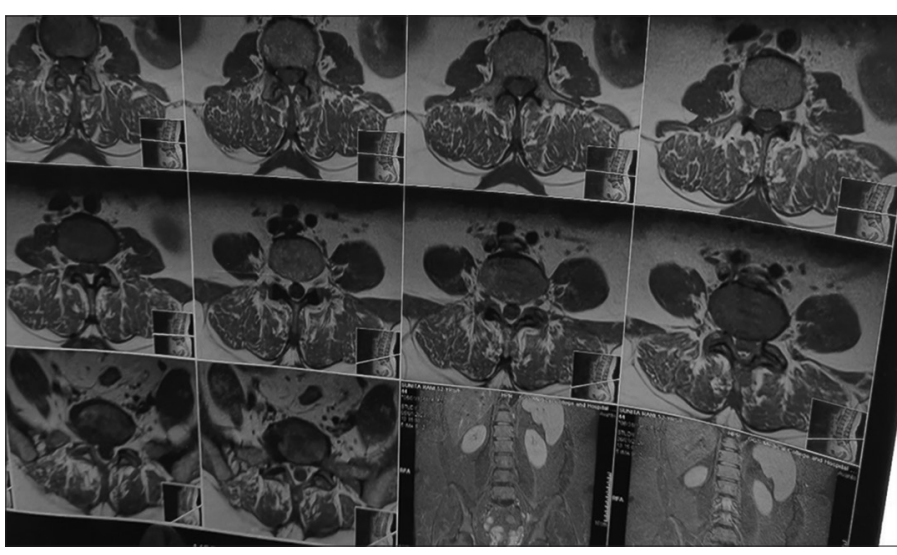

Figure 1: Magnetic resonance imaging image of the lumbar spine of the patient

products were kept ready. On the day of surgery, after confirming fasting, nebulization was done with $4 \mathrm{ml}$ of $4 \%$ xylocaine for $15 \mathrm{~min}$, followed by gargles with viscous xylocaine. Standard American Society of Anesthesiologists (ASA) monitors were attached with five lead electrocardiogram (ECG) showing normal sinus rhythm, non-invasive blood pressure (NIBP) was160 / $90 \mathrm{mmHg}$, and $\mathrm{SpO} 2$ was $98 \%$ on room air. The temperature probe and bispectral index (BIS) monitor were connected. An intravenous line was established.

The epidural block was performed through median approach at $\mathrm{T} 12$ region and $0.25 \%$ ropivacaine $20 \mathrm{ml}$ was given. Then the patient was made supine. Preoxygenation was done with $100 \%$ oxygen for $3 \mathrm{~min}$. Induction performed with graded doses of propofol $(100 \mathrm{mg}+50 \mathrm{mg}+50 \mathrm{mg})$. After the loss of verbal contact, the patient was ventilated with oxygen and sevoflurane and when the depth of BIS reached around 35, laryngoscopy was done using C-MAC. Vocal cords and the laryngeal cavity were anesthetized with $10 \%$ lox spray. Intermittent positive pressure ventilation was done to spread the local anesthetic inside. Patient was intubated with a $7.5 \mathrm{~mm}$ endotracheal tube at BIS 35, without the use of muscle relaxants. After intubation, the endotracheal tube was fixed at $21 \mathrm{~cm}$ and the patient was made prone after padding on all pressure points.

Maintenance of anesthesia was done using $\mathrm{O}_{2}+\mathrm{N}_{2} \mathrm{O}+$ sevoflurane (0.2-2\%) and propofol infusion $(10-15 \mathrm{mcg} / \mathrm{kg} / \mathrm{min})$. Sevoflurane and propofol were titrated to keep BIS between 35 and 45 . The temperature was maintained at $36^{\circ} \mathrm{C}$. Fentanyl $(0.5 \mu \mathrm{g} / \mathrm{kg})$ and paracetamol $(1000 \mathrm{mg})$ were used for analgesia. Intraoperative hemodynamics was maintained. No blood transfusion was required. Total blood loss was around 200-250 ml. The surgery lasted for $4 \mathrm{~h}$. Propofol infusion was stopped $10 \mathrm{~min}$ before completion of sutures. At the end of the surgery, the patient was made supine. Sevoflurane stopped after repositioning. After 5-7 min of repositioning, the patient was able to open up her eyes and generate good tidal volume. BIS value increased to $80-85$ and this time, the patient was extubated.

Post-operative monitoring was done in ICU and the patient was discharged on the $7^{\text {th }}$ day, postoperatively. She had an uneventful hospital stay. The patient was followed up after 15 days of discharge with no post-operative complications and was relieved from the complaint of pain which she had before surgery.

\section{DISCUSSION}

Successful perioperative management of the patient with myasthenia gravis is a real challenge for anesthesiologists. There is always a risk of postoperative ventilatory complications, cholinergic, and myasthenic crises.

In the pre-operative visit, it is important to focus on the respiratory system, bulbar symptoms, and neurological assessment. Thus, pre-operative pulmonary function tests are necessary. They can help to decide certain critical decisions such as extubation and the need for post-operative mechanical ventilation [9]. Preoperatively cholinesterase inhibitors (pyridostigmine) continuation is debated. The patients who do not receive the morning dose of pyridostigmine on the day of surgery are at risk of developing respiratory distress and may need neostigmine. However, discontinuation of pyridostigmine also gives an advantage of the quicker onset of non-depolarizing muscle relaxants and requiring smaller doses. Steroid-dependent patients usually require pre-operative coverage. Thyroid medications also need to be continued. The patients who are unresponsive to medication may require pre-operative plasmapheresis.

Regional anesthesia is the preferred technique in a patient with myasthenia gravis because it avoids the need for benzodiazepines, opioids, and neuromuscular blockers [9]. If local anesthetics are to be used, amides (Ropivacaine, Bupivacaine, Lidocaine, and Mepivacaine) should be preferred over esters in patients who are taking anti-cholinesterases because anti-cholinesterases impairs hydrolysis of ester local anesthesia and may lead to the prolonged blockade. However, in surgeries where general anesthesia is inevitable, balanced anesthesia is advocated [10]. It can be the inhalational-intravenous combination or only an intravenous approach.

The goals of anesthesia are smooth induction, intraoperative hemodynamic stability, rapid emergence, and early extubation to make out any neurological deficits. In this case, we used a combination of general and epidural anesthesia to reduce the requirement of drugs in general anesthesia. In general anesthesia, we preferred a neuromuscular-free approach and inhalational-intravenous combination (Sevoflurane - propofol) with maintenance on a combination of $\mathrm{O}_{2}, \mathrm{~N}_{2} \mathrm{O}$, Sevoflurane, and Propofol. Among inhalational and intravenous agents, sevoflurane and propofol are the preferred agents, respectively, due to their pharmacological properties [11].

Pre-medication with sedatives should also be used with caution as these patients are highly susceptible to respiratory depression. Perioperative use of benzodiazepines, beta-blockers, antibiotics (aminoglycosides, ampicillin, macrolides, and fluoroquinolones), diuretics, anti-epileptics, and calcium channel blockers can induce myasthenic crisis; hence, extreme caution is required with its use [4].

Neuromuscular blockers should be used with care as the patient response to muscle relaxants is very unpredictable. Regarding 
succinylcholine, the patients are often resistant to the drug and require a large dose to obtain maximal blockade [12]. This can be explained by a residual number of receptors hindering the drug from effectively depolarizing the motor end-plate. However, the patients who have undergone plasmapheresis or are using anticholinesterase drugs preoperatively can have a potentiating effect of succinylcholine [7]. Effects are inversely proportional to the activity of plasma cholinesterase [13]. Moreover, there is a highrisk of Phase II block with succinylcholine.

When it comes to non-depolarizing muscle relaxants, these patients are typically very sensitive and they always remain at risk of residual neuromuscular blockade $[14,15]$. Adequate pain relief is a must, as inadequately managed pain can precipitate a myasthenic crisis. These patients require meticulous monitoring. Along with routine monitoring (5 lead ECG, SpO2, NIBP), these patients require BIS monitoring to know the depth of anesthesia and provide the additional drugs, if required. Electromyography and mechanomyography are the preferred methods for monitoring neuromuscular transmission. Train of four monitoring would guide for the requirement of neuromuscular blockers intraoperatively and for reversal. Both hypothermia and hyperthermia can precipitate myasthenic crisis; hence, temperature monitoring is also important. Extubation in such patients is always a tricky situation. However, with meticulous monitoring and appropriate technique, the patient can be extubated. Hence, it is preferable to use regional anesthesia whenever possible, if general anesthesia is deemed necessary, it is better to use a balanced approach.

\section{CONCLUSION}

Despite recent advances in technologies, myasthenia gravis is still a challenge for anesthesiologists. Successful management of such patients requires adequate preoperative preparation, selection of adequate techniques, and meticulous perioperative monitoring.

\section{REFERENCES}

1. Grob D, Brunner N, Namba T, Pagala M. Lifetime course of myasthenia gravis. Muscle Nerve 2008;37:141-9.

2. Pasnoor M, Wolfe GI, Nations S, Trivedi J, Barohn RJ, Herbelin L, et al. Clinical findings in MuSK-antibody positive myasthenia gravis: A U.S. experience. Muscle Nerve 2010;41:370-4.

3. Meyer A, Levy Y. Geoepidemiology of myasthenia gravis. Autoimmun Rev 2009;9:A383-6.

4. Maselli RA. Pathophysiology of myasthenia gravis and Lambert-Eaton syndrome. Neurol Clin 1994;12:285-303.

5. Sarkar S, Mandal K. Hypokalemic periodic paralysis accompanied with myasthenia gravis: A case report. Internet J Anesthesiol 2008;16:2.

6. Engel AG. Neuromuscular manifestations of Graves' disease. Mayo Clin Proc 1972;47:919-25.

7. Baraka A. Anaesthesia and myasthenia gravis. Can J Anaesth 1992;39:476-86.

8. De Souza Neto EP, Módolo NS. Miastenia gravis: Implicações anestésicas. Rev Bras Anestesiol 1993;43:373-82.

9. Abel M, Eisenkraft JB. Anesthetic implications of myasthenia gravis. Mt Sinai J Med 2002;69:31-7.

10. Burgess FW, Wilcosky B Jr. Thoracic epidural anesthesia for transsternal thymectomy in myasthenia gravis. Anesth Analg 1989;69:529-31.

11. Maddali MM, Matreja PV, Zachariah M. Bispectral index-monitored anesthesia technique for transsternal thymectomy. Asian Cardiovasc Thorac Ann 2009; 17:389-94.

12. Eisenkraft JB, Book WJ, Mann SM, Papatestas AE, Hubbard M. Resistance to succinylcholine in myasthenia gravis: A dose-response study. Anesthesiology 1988;69:760-3.

13. Baraka A. Suxamethonium block in the myasthenic patient. Correlation with plasma cholinesterase. Anaesthesia 1992;47:217-9.

14. Nilsson E, Meretoja OA. Vecuronium dose-response and maintenance requirements in patients with myasthenia gravis. Anesthesiology 1990;73:28-32.

15. Itoh H, Shibata K, Nitta S. Sensitivity to vecuronium in seropositive and seronegative patients with myasthenia gravis. Anesth Analg 2002;95:109-13.

Funding: None; Conflicts of Interest: None Stated.

How to cite this article: Kaur B, Singh G, Kaur H, Singh I. Anesthetic implications in patients with myasthenia gravis undergoing spine surgery. Indian J Case Reports. 2021;7(4):128-130. 